University of Wollongong

Research Online

Faculty of Informatics - Papers (Archive)

Faculty of Engineering and Information

Sciences

December 2003

\title{
Monitoring of wheel dressing operations for precision grinding
}

Li Xue

University of Wollongong, Ix77@uow.edu.au

Fazel Naghdy

University of Wollongong, fazel@uow.edu.au

C. Cook

University of Wollongong, chris_cook@uow.edu.au

Follow this and additional works at: https://ro.uow.edu.au/infopapers

Part of the Physical Sciences and Mathematics Commons

\section{Recommended Citation}

Xue, Li; Naghdy, Fazel; and Cook, C.: Monitoring of wheel dressing operations for precision grinding 2003. https://ro.uow.edu.au/infopapers/82

Research Online is the open access institutional repository for the University of Wollongong. For further information contact the UOW Library: research-pubs@uow.edu.au 


\title{
Monitoring of wheel dressing operations for precision grinding
}

\author{
Abstract \\ In grinding operation, on-line process monitoring of dressing will ensure the quality of the grinding wheel \\ and will achieve reproducible surface finish. The results of a study conducted to evaluate the feasibility \\ and effectiveness of Acoustic Emission (AE) sensors in online monitoring of dressing is reported. Two \\ aspects of the process are addressed. The first is the detection of undesired wheel conditions, such as an \\ out-of-round wheel and wheel contour errors. The other is improving the surface finish of the ground \\ workpiece by monitoring the dressing parameters. Experimental results indicate that AE signal can be \\ effectively used to identify the faults that might occur during dressing. This in turn will result in better \\ surface finish in the machined workpiece. \\ Keywords \\ condition monitoring, grinding, machining \\ Disciplines \\ Physical Sciences and Mathematics \\ Publication Details \\ This paper originally appeared as: Xue, L, Naghdy, F \& Cook, C, Monitoring of wheel dressing operations \\ for precision grinding, FIEEE International Conference on Industrial Technology, 11-14 December 2002, 2, \\ 1296-1299. Copyright IEEE 2002.
}




\title{
Monitoring of Wheel Dressing Operations for Precision Grinding
}

\author{
Li Xue, Fazell Naghdy and Chris Cook \\ School of Electrical, Computer and Telecommunications Engineering, University of Wollongong, \\ Wollongong NSW 2522 Australia \\ Email: lx01@st.elec.uow.edu.au, Phone: +6124221 3535, Fax: +61242213236
}

\begin{abstract}
In grinding operation, on-line process monitoring of dressing will ensure the quality of the grinding wheel and will achieve reproducible surface finish. The results of a study conducted to evaluate the feasibility and effectiveness of Acoustic Emission (AE) sensors in online monitoring of dressing is reported. Two aspects of the process are addressed. The first is the detection of undesired wheel conditions, such as an out-of-round wheel and wheel contour errors. The other is improving the surface finish of the ground workpiece by monitoring the dressing parameters. Experimental results indicate that $\mathrm{AE}$ signal can be effectively used to identify the faults that might occur during dressing. This in turn will result in better surface finish in the machined workpiece.
\end{abstract}

Keywords: Monitoring, Dressing, Acoustic Emission, Grinding

\section{Introduction}

Dressing is the process of conditioning the grinding wheel surface in order to reshape the wheel when it has lost its original shape through wear. This will generate a satisfactory grinding wheel topography, which has significant impact on the grinding force, eniergy, temperatures, wheel wear and surface finish $[1,2]$. In the single-point diamond tool dressing, a number of parameters govern the process including dressing depth, dressing lead/ traverse rate, shape of diamond tip and number of dressing passes [3]. These parameters also affect the grinding behaviour and the surface finish of the workpiece. Generally, fine dressing with a low dressing lead and small dressing depth produces a wheel with a high density of blunt cutting points $[1,4]$. As a result, the wheel generates high cutting forces $[3,5,6]$, increased temperature [1], good surface finish $[3,5,7$; $8]$ and low wheel wear rates $[1,4]$. A change in the shape of the dresser through wear results in a decreased wheel wear rate in grinding process [9].

The number of dressing passes depends upon the depth of loading, grit size, and the depth of the wear pattern to be removed [3]. Usually, the effects of previous dressing and grinding conditions can be eliminated through three [3] or four [10] successive passes. Dressing errors, however, can diversely affect the quality of dressing wheel as the result of fluctuations in real dressing depth, dresser wear and other disturbances [11]. Such undesired conditions can be detected through an in process monitoring system. Further dressing passes will remove the identified imperfections in the wheel.

Acoustic emission (AE) sensors have proved superior over the other sensors used in grinding such as force sensors and active current sensing of machine drives [11], due to their temperature stability, high sensitivity and high dynamics. Furthermore, AE sensors are inexpensive and easy to mount. Hence, a number of researchers have employed $\mathrm{AE}$ sensors for in-process monitoring of dressing. AE sensors have been used for detecting dresser-wheel contact $[12,13]$, monitoring dressing depth [7] and dressing lead [5, 7], and diagnosing dressing faults $[11,13]$.

The aim of the work reported in this paper is to evaluate the feasibility and effectiveness of monitoring the dressing of the grinding wheel using an $\mathrm{AE}$ sensor. In the course of the paper, the experimental set up will be described. The details of various experimental scenarios implemented for monitoring of the grinding wheel dressing will be explained. The results obtained will be critically analysed and some conclusions will be drawn.

\section{Experimental Set-up}

A manual surface-grinding machine has been modified for use in this study. The movements on the grinding table traverse (x-axis) and the wheel (z-axis) are automated. The table speed and wheel position are controlled by a DSP card under the control of a host computer. The displacements on $\mathrm{x}$-axis and $\mathrm{z}$-axis are measured by motor's encoders. The resolutions of up to $1.25 \mu \mathrm{m}$ and $0.5 \mu \mathrm{m}$ can be achieved on $\mathrm{z}$ on $\mathrm{x}$ axes respectively. The original arrangement for cross feed (y-axis) is maintained.

The experimental set-up is shown in Figure 1. The Acoustic emission (AE) signal generated by interaction between the dresser and the grinding wheel is coupled by grease to a dresser-holder and detected by an $\mathrm{AE}$ sensor which is attached to the dresser-holder. Then, the AE signal is amplified and filtered by a band-pass filter with a bandwidth of $100 \mathrm{kHz}-1200 \mathrm{kHz}$ in order to remove unwanted signals produced by the machine vibration and environmental noise. The dressing energy is characterized in terms of root mean square (RMS) value of the AE signal. An RMS-chip with an average time constant of $1 \mathrm{~ms}$ is employed to calculate the RMS value. The AErms is digitised either by a digital CRO, or by an ISA data acquisition card and then stored in a PC. The displacement of the grinding wheel relative to the dresser is measured by an encoder. 


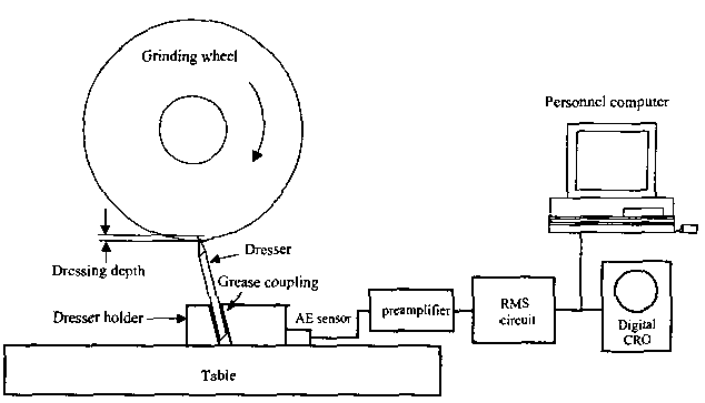

Fig. 1 Experimental Set-up

\section{Monitoring of Dressing Process}

This study is focused on two aspects of the dressing process. The first is the detection of undesired wheel conditions, such as an out-of-round wheel and wheel contour errors. The other is to improve the surface finish of the ground workpiece by monitoring the dressing parameters. A series of experiments have been designed and carried out to develop a better understanding of how AE signal can assist in monitoring these two phenomena.

\subsection{Detection of Out-of-Round Wheel}

Usually, a new assembled wheel is eccentric relative to the spindle axis (out-of-round). An out-of-round wheel produces a visible vibration pattern on the workpiece during grinding, resulting in a poorly finished workpiece. Therefore, it is important that the wheel is dressed after assembly. In this process, the wheel is brought into concentricity relative to the spindle axis. This operation is also known as trueing.

The experiments conducted show that the AE signal can be used to detect an out-of-round wheel. Figure 2 illustrates the $\mathrm{AE}$ signal produced from an out-of-round wheel during a series of dressing passes. In this case, the dressing depth is fixed to $20 \mu \mathrm{m}$ and the dressing lead is operated manually across the width of the grinding wheel. This diagram illustrates the variation of $\mathrm{AE}(\mathrm{rms})$ levels in the third, fifth and eighth dressing passes resulted from significant fluctuations in the dressing depth caused by the out-of-round wheel. A stable $A E(r m s)$ signal is finally achieved in the tenth dressing pass, indicating that the wheel has become concentric.

\subsection{Detection of Wheel Contour Error}

The wheel contour error can be also detected by monitoring the AE signal. This indicates whether the dressing depth has remained constant during operation or not. In this experiment, a contour error is intentionally introduced along the wheel face. The $\mathrm{AE}(\mathrm{rms})$ values of $2^{\text {nd }}, 6^{\text {th }}$ and $8^{\text {th }}$ dressing passes are shown in Figure 3. As the dresser moves across the wheel face, the contour error causes the dressing depth to change. This results in a sharp fall in the $A E(\mathrm{rms})$ value. According to the obtained results, the contour error introduced on the wheel is removed after eight dressing passes.
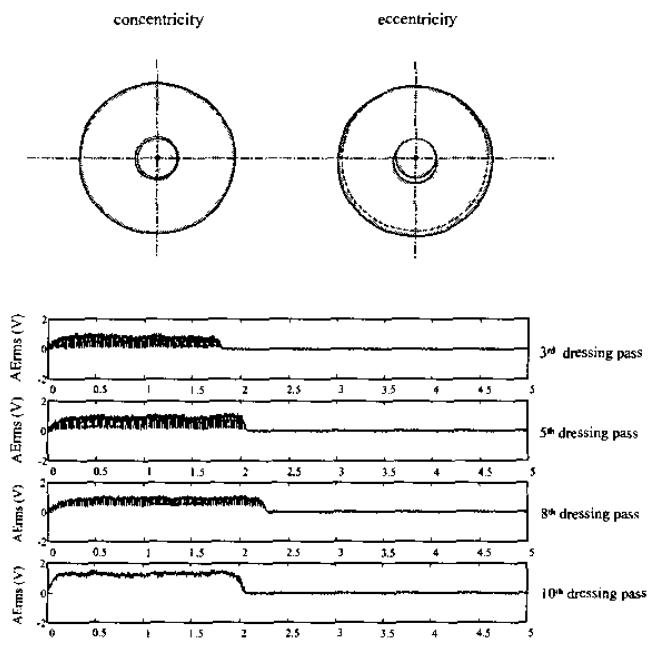

Time (sec)

Fig. 2 Out-of-Round Grinding Wheel and the Corresponding AE Signal during Dressing Passes
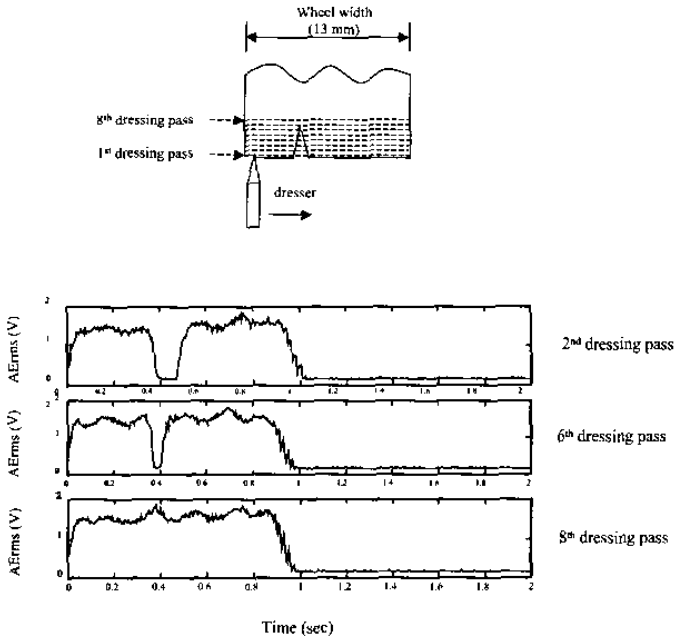

Fig. 3 Wheel Contour Error and the Corresponding AE Signal during Dressing Passes.

\subsection{Monitoring of Dressing Parameters}

The dressing lead and dressing depth are important parameters in the dressing process. The dressing depth is controlled according to the information received from the encoder on the z-axis of the grinding machine. 
However, the dressing lead fluctuates unexpectedly in each dressing pass and among all the dressing passes as the cross-feed (y-axis) of the machine is operated manually. Consequently, it is difficult to maintain a constant dressing quality. This also influences the surface roughness of the workpiece. Figure 4 shows the effect of the fluctuation of the dressing lead on the surface roughness in comparison with the influence of the grinding parameters such as the depth of cut and the table speed.

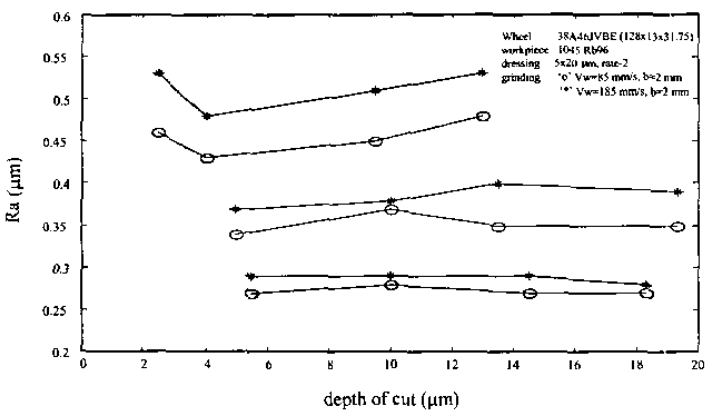

Fig. 4 Influence of Dressing and Grinding Conditions on the Surface Roughness of Workpiece.

In this experiment, the wheel is dressed by setting the dressing down-feed to $20 \mu \mathrm{m}$. The dressing lead is controlled manually and is maintained as stable as possible. Depending on the loading condition, five to ten dressing passes are taken. Eight sections in four workpieces are then ground by applying eight grinding conditions separately. In order to prevent unstable roughness caused by rapid wheel wear in the starting stage, the surface roughness of the ground workpieces is measured off-line when the specific material removal is about $100 \mathrm{~mm}^{3} / \mathrm{mm}$.

The pair of curves with a solid dash line in Figure 4 shows the effect of the depth of cut and the table speed on the roughness of workpiece. Two more pairs of curves with different dash styles are obtained by repeating the above procedures. The difference of surface roughness observed in the three experiments is caused mainly by the fluctuations of dressing leads. According to the results shown in Figure 4, the dressing lead is a major factor affecting the surface finish.

The possibility of producing more consistent wheel quality by monitoring and controlling dressing lead on the machine is investigated through further experiments. The average dressing lead across whole wheel width is monitored by measuring the time of the dresser-wheel contact using $\mathrm{AE}(\mathrm{rms})$ signal. If the time related in the last dressing pass is proved to be different from the expected value, a further dressing pass is carried out to ensure consistent average dressing lead. Using these monitoring strategics, more consistent results with less variation in the surface roughness can be produced, as shown in Table 1.

Table 1 Effects of Monitoring Dressing on Variation in Surface Roughness

\begin{tabular}{|c|c|c|c|c|c|}
\hline \multicolumn{3}{|c|}{$\begin{array}{c}\text { grinding with } \\
\text { monitoring dressing lead }\end{array}$} & \multicolumn{3}{|c|}{$\begin{array}{c}\text { grinding without } \\
\text { monitoring dressing lead }\end{array}$} \\
\hline $\begin{array}{c}\mathrm{Ra} \\
(\mu \mathrm{m})\end{array}$ & $\begin{array}{l}\text { mean } \\
\text { value } \\
(\mu \mathrm{m})\end{array}$ & $\begin{array}{l}\text { average } \\
\text { deviation }\end{array}$ & $\begin{array}{c}\mathrm{Ra} \\
(\mu \mathrm{m})\end{array}$ & $\begin{array}{l}\text { mean } \\
\text { value } \\
(\mu \mathrm{m})\end{array}$ & $\begin{array}{l}\text { average } \\
\text { deviation }\end{array}$ \\
\hline $\begin{array}{l}0.43 \\
0.34 \\
0.36 \\
0.36\end{array}$ & 0.37 & $8 \%$ & $\begin{array}{l}0.45 \\
0.37 \\
0.28\end{array}$ & 0.37 & $16 \%$ \\
\hline
\end{tabular}

\section{Conclusions}

The work conducted on monitoring the dressing process in grinding using $\mathrm{AE}$ signal has been reported. A series of experiments has been conducted to understand the effectiveness of $\mathrm{AE}$ signal for in process identification of dressing errors, and hence producing a more consistent surface finish in the consequent grinding operations. The following outcomes have been obtained:

- The dressing lead is the most important factor affecting the surface roughness compared with other grinding parameters such as the depth of cut and the table speed.

- Monitoring of the dressing parameters results in a more consistent surface roughness in the consequent grinding operations.

- Such on line monitoring can also reveal whether the dressing depth has remained constant during the process or not.

\section{Acknowledgements}

This work is part of a project funded by the Australian Federal Government Cooperative Research Centre for Intelligent Manufacturing System Technology.

\section{References}

[1] J. Verkerk, TH Delft/NL and A. J. Pekelharing, "The influence of the dressing operation on productivity in precision grinding," Annals of the CIRP, Vol. 28/2,1979, pp. 487-495.

[2] S. Malkin, "Grinding technology theory and applications of machining with abrasives," Ellis Horwood Limited, 1989.

[3] Milton C. Shaw, "Principles of abrasive processing," Clarendon Press, Oxford, 1996.

[4] J. Verkerk, TH Delft/NL and A. J. Pekelharing, "Kinematical approach to the effect of wheel dressing conditions on the grinding process," Annals of the CIRP, Vol. 25/1,1976, pp. 209-214.

[5] J. Webster et al., "Acoustic emission for process control and monitoring of surface integrity during 
grinding," Annals of the CIRP, Vol. 43/1, 1994, pp. 299-304.

[6] X. Chen, et al, "Analysis and simulation of the grinding process. Part III: comparison with experiment," Int. J. Mach. Tools Manufact. Vol. 36, 1996, pp. 897-906.

[7] I. Inasaki, "Monitoring of dressing and grinding process with acoustic emission signals," Annals of the CIRP, Vol. 34/1, 1985, pp. 277-280.

[8] N. P. Fletcher, "A simple model for predicting the prossible surface roughness of a cylindrically traverse ground workpiece, when using wheels dressed with signal point diamond tools," Proceedings of the $21^{\text {st }}$ International Machine Tool Design and Research Conference, 1980, pp. 329 336.

[9] J. Verkerk, "Characterisation of wheel wear in plunge grinding," Annals of the CIRP, Vol. 26/1,1977, pp. 127-131.
[10] E. J. Pattinson and J. Lyon, "The collection of data for the assessment of grinding wheel dressing treatment," Proceedings of the $15^{\text {th }}$ International Machine Tool Design and Research Conference,., Vol. 15, 1975, pp. 317-323.

[11] W. Konig and H. P. Meyen, "AE in grinding and dressing: accuracy and process reliability," Proc. of $4^{\text {th }}$ Int. Grind. Conference, 1990, MR90-526.

[12] J. F. Gomes de Oliveira, D. A. Dornfeld and B. Winter, "Dimensional characterization of grinding wheel surface through acoustic emission," Annals of the CIRP, Vol. 43/1, 1994, pp. 291-294.

[13] Karpuschewski, M. Wehmeier and I. Inasaki, "Grinding monitoring system based on power and acoustic emission sensors," Proceedings of the $50^{\text {th }}$ CIRP General Assembly Conference, 2000, pp. 235 . 